\title{
Analysis of the clinical factors associated with anal function after intersphincteric resection for very low rectal cancer
}

\author{
Tadao Tokoro*, Kiyotaka Okuno, Jin-ichi Hida, Kazuki Ueda, Tahehito Yoshifuji, Koji Daito, Masako Takemoto
} and Fumiaki Sugiura

\begin{abstract}
Background: Intersphincteric resection (ISR) has been used to avoid permanent colostomy in very low rectal cancer patients. This study aimed to assess the surgical safety and oncologic and functional outcomes of ISR.

Methods: The records of 30 consecutive very low rectal cancer patients who underwent ISR without neoadjuvant therapy were retrospectively analyzed; survival and locoregional recurrence rates were calculated by the Kaplan-Meier method. Incontinence was assessed by a functionality questionnaire and the Wexner score.

Results: The median distance between the distal margin of the dentate line was $10 \mathrm{~mm}$. A total of 12, 4, and 14 patients underwent partial ISR, subtotal ISR, and total ISR, respectively. The mean distal resection margin was negative in all cases, and circumferential resection margin was positive in two cases. Morbidity was 33.3\%: anastomotic stricture in seven patients, colonic J-pouch prolapse in two patients, and an anovaginal fistula in one patient. During the median, 56.2-month follow-up period, local, distant, and combined recurrences occurred in four, three, and two patients, respectively. The 5-year overall and disease-free survival rates were $76.5 \%$ and $68.4 \%$, respectively. Local recurrence rates were $5.2 \%$ for the patients with Tis-T2 tumors as compared with $45.5 \%$ for those with T3 tumors $(P=0.008)$. The mean Wexner scores and stool frequencies, 12 months after stoma closure in 19 patients, were 11.5 and 6.6 per $24 \mathrm{~h}$, respectively. Significant differences were not seen in the Wexner scores between partial ISR and subtotal/total ISR $(11.8 \pm 2.6$ and $9.1 \pm 5.6)$. Stool frequency $(P=0.02)$, urgency $(P=0.04)$, and fragmentation $(P=0.015)$ were worse in patients with anastomotic stricture than in those without; there was no symptom improvement in patients with anastomotic stricture.
\end{abstract}

Conclusions: The anastomotic strictures in patients undergoing ISR may have negatively affected anal function. For total ISR patients, at least, informed consent stating the possibility of a permanent colostomy is necessary.

Keywords: Intersphincteric resection, Very low rectal cancer, Wexner score

\section{Background}

Over the last two decades, surgical treatment for patients with very low rectal cancer has radically evolved, allowing permanent colostomy to be avoided in these patients. Reappraisal of the distal margin has allowed increased potency of sphincter-preserving resections. Moreover, total mesorectal excision (TME) [1], coupled with techniques such as end-anal stapling and coloanal anastomosis using the double-stapling technique (DST) [2], can be used to

\footnotetext{
* Correspondence: tokoro@surg.med.kindai.ac.jp

Department of Surgery, Kinki University, Faculty of Medicine, 377-2,

Ohno-Higashi, Osaka-Sayama, Osaka 589-8511, Japan
}

preserve the sphincter without compromising on the oncological results [3-5].

However, when the tumor is located close to the dentate line, conventional anterior resection using the interperitoneal approach with DST may not allow a secure distal resection margin. To resolve this problem, partial or total internal sphincteric resection (ISR) and coloanal anastomosis per anus can be used for safe surgical resection of the tumor [6-11]. ISR has been proposed to achieve distal clearance in selected patients with very low rectal tumors extending to the upper part of the internal sphincter muscle. Furthermore, it has been

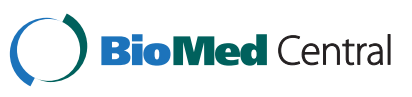


proposed to restore the anal structure, preserve fecal continence, and reduce the numbers of patients requiring a permanent stoma.

ISR has been widely recognized to achieve a safe distal resection margin, which can be as small as 1 to $2 \mathrm{~cm}$ $[12,13]$. However, with this procedure, which involves dividing the rectum between the internal sphincter and the external sphincter or the levator ani, it remains unclear whether a secure circumferential resection margin (CRM) of the tumor can be obtained. Further, partial or total ISR procedures have been shown to possibly interfere with fecal continence [7,8,14-16].

Anal incontinence is considered to influence various factors in patients receiving ISR, including preoperative radiation therapy $[17,18]$, reconstruction methods [9], extent of sphincter preservation [19], tumor level, and height of the anastomosis [20]. Moreover, fecal incontinencerelated quality of life (QOL) scores were poorer in ISR patients than the patients with low anterior resection [16]. Although ISR was proposed as an alternative procedure to avoid abdominoperineal resection (APR), a colostomy is a viable option for patients who suffer from fecal incontinence, which offers a definitive cure along with an improved quality of life [21].

To evaluate the feasibility of ISR in very low rectal cancer patients, it is necessary to clarify the oncologic results and functional outcomes related to this procedure. The aims of this study were to evaluate the surgical safety of the procedure, to assess its oncologic and functional outcomes, and to identify factors predictive of anal dysfunction in the absence of radiotherapy.

\section{Methods}

\section{Patients}

We reviewed the medical charts of all 30 consecutive patients who had undergone ISR for very low rectal adenocarcinoma between April 2001 and August 2010 at the Department of Surgery, Faculty of Medicine, Kinki University. Written informed consent forms concerning this procedure were obtained for all patients in our hospital. In all cases, tumor stage was evaluated before surgery by digital examination; colonoscopy; chest, abdominal and pelvic computed tomography (CT); and pelvic magnetic resonance imaging (MRI). Anorectal manometry was not routinely performed. Preoperative criteria for the exclusion of patients for ISR were clinical T4 tumors, poorly differentiated adenocarcinoma (revealed by biopsy specimens), infiltrating gross appearance of the tumors, and some degree of preoperative incontinence. Among patients with T1 tumors considered for transanal local excision, ISR was proposed for those patients with a risk of lymph node metastases in the case of tumors with adverse pathologic features. Resectable distant metastases were not a preoperative exclusion criterion for ISR, and therefore, ISR was performed in one patient with synchronous liver metastasis.

The histopathological findings and tumor stage classification were based on the Union for International Cancer Control (UICC) TNM classification (seventh edition) [22]. In Japan, preoperative chemoradiotherapy (CRT) for resectable T3 rectal tumors, irrespective of lymph node involvement, was not routinely performed, and none of the patients included in this study had received preoperative CRT or pre or postoperative radiotherapy.

\section{Surgical technique}

The principle of the ISR procedure is based on an anatomic dissection plane between the internal sphincter muscle, which is an extension of the muscular layer of the rectum, and the external sphincter muscle. Surgical intervention was commenced with a high ligation of the inferior mesenteric artery using the abdominal approach. The rectum was dissected to the levator ani with TME. Further, the intersphincteric plane was entered from the nearest anorectal junction if possible. If this dissection was technically difficult to perform until a sufficient distal margin was obtained via the abdominal approach, then the transanal approach of the operation was commenced after perineal exposure using a retractor (Lone Star retractor, Lone Star Medical Products Inc, Houston, TX, USA). The distal margin was $1 \mathrm{~cm}$ for Tis-T2 tumors, and $2 \mathrm{~cm}$ below the inferior extent of the tumor for T3 tumors. Total ISR involved complete excision of the internal sphincter muscle, that is, the distal line of resection was along the intersphincteric groove. For partial ISR, the distal resection line was along the dentate line, and for subtotal ISR, the distal resection line ran from the dentate line to intersphincteric groove $[11,19]$. If the tumor was close to the external sphincter or the levator ani muscle, additional partial external sphincter resection (ESR) [11] was performed.

The proximal rectal side of the cut edge was immediately closed and irrigated with $1,500 \mathrm{ml}$ of a $5 \%$ povidone-iodine solution to reduce the risk of tumorcell dissemination $[7,23]$. Then, the dissection was carried out longitudinally along the plane between the internal and external sphincters to reach the abdominal excision. After the rectum was removed through the abdomen, colonic J-pouch and anal anastomosis procedures with interrupted suture were performed. The anastomosis was protected with a diverting loop ileostomy or transverse colostomy in all the patients.

\section{Follow-up and local recurrences}

All 30 patients were followed for a median of 56.2 months (range; 13.3 to 168.4 months), and 20 patients were available for follow-up for more than 2 years. All 
patients were followed using a standardized protocol, including a clinical examination with digital palpation, and laboratory tests, including tumors markers (carcinoembryonic antigen (CEA), CA-19-9), every 3 months for the first 3 years, and then every 6 months for 2 years, and then once a year. Abdominal and pelvic computed tomography and chest radiography were performed every 6 months for the first 3 years. A colonoscopy was performed 3 or 6 months after surgery for planning stoma closure, and then once every year for 3 years. Most patients with stage III rectal cancer received postoperative chemotherapy with oral tegafur, uracil, and/or folic acid for 6 to 12 months. Local recurrence was defined as the presence of any anastomotic, pelvic, or lateral node recurrences documented either by clinical or pathologic exanimation, irrespective of the presence of distant metastases.

\section{Anal functional assessments}

Functional outcomes were assessed using our functional questionnaire. We prospectively collected questionnaires regarding anal function from our patients every 3 months after closure of the diverting stoma. In this questionnaire, patients were asked about stool frequency (number of bowel movements per 24 h), fecal urgency (ability to defer stool evacuation for $>15$ minutes), stool fragmentation (>2 evacuations in $1 \mathrm{~h}$ ), dyschesia (taking more than 15 minutes to defecate), nocturnal defecation, use of intestinal transit regulators, and need to wear a pad. Incontinence was assessed by the Wexner continence score [24], and we considered anal function to be poor if the Wexner score was 15 or more at 12 months $[17,18]$. Anastomotic stricture or occlusion was determined when the surgeon's forefinger could not pass through the anastomotic site 3 months after surgery.

\section{Statistical analysis}

Statistical analyses were performed using JMP10 software (SAS Institute Inc., Cary, NC, USA). Overall and disease-free survival were analyzed using Kaplan-Meier curves and the log rank test. For disease-free survival, patients who failed locally, systemically, or both were censored at the time of the first failure.

Univariate and multivariate regression analyses were used to evaluate the impact of age, gender, type of surgery, type of reconstruction, and anastomotic stricture. The changes in anal function between the different groups of patients over time were compared using Wilcoxon signed-rank test, and comparisons between the anastomotic stricture group and the non-stricture groups were performed using the Mann-Whitney U test. Statistical significance was indicated at the $P<0.05$ level.

\section{Results}

Patients and tumor characteristics are shown in Table 1.

During the study period, ISR covered 144 patients (26.3\%) who underwent surgery for lower-third rectal cancer, located below the peritoneal reflex, 49 patients of conventional anterior resection with DST, 35 patients of abdominoperineal resection, and 20 patients of local excision. The study population was made up of 30 patients (16 men and 14 women) with a median age of 58.9 years (range, 31 to 75 years); 1 patient (3.3\%) had a pTis of a large villous tumor, 8 patients had a pT1 tumor (26.7\%), 10 patients had a pT2 tumor (33.3\%) and 11 patients had a pT3 tumor (36.7\%). According to the UICC TNM classification system, the tumors were classified as stage 0 in 1 patient, stage I in 16 patients, stage IIA in 5 patients, stage IIIB in 5 patients, and stage IVA in 1 patient.

Table 1 Clinicopathological characteristics of patients who received intersphincteric resection $(n=30)$

\begin{tabular}{|c|c|}
\hline Characteristic & Value \\
\hline Age, years ${ }^{a}$ & $60.5 \pm 9.9$ \\
\hline \multicolumn{2}{|c|}{ Histopathological grade ${ }^{b}$} \\
\hline G1 & 12 \\
\hline G2 & 16 \\
\hline Muc & 2 \\
\hline \multicolumn{2}{|l|}{ Tumor location } \\
\hline Anterior wall & 14 \\
\hline Posterior wall & 12 \\
\hline Left wall & 1 \\
\hline Right wall & 2 \\
\hline Circ & 1 \\
\hline Tumor size, $\mathrm{cm}^{\mathrm{a}}$ & $3.8 \pm 1.5$ \\
\hline$<4 \mathrm{~cm}$ & 18 \\
\hline$\geq 4 \mathrm{~cm}$ & 12 \\
\hline \multicolumn{2}{|l|}{ pT stage } \\
\hline Tis & $1(3.3 \%)$ \\
\hline $\mathrm{T} 1$ & $8(26.7 \%)$ \\
\hline $\mathrm{T} 2$ & $10(33.3 \%)$ \\
\hline T3 & 11 (36.7\%) \\
\hline
\end{tabular}

TNM stage

0

I

IIA

IIIA

IIIB

IVA

${ }^{\mathrm{a}}$ Values denote mean $\pm \mathrm{SD}$.

${ }^{b}$ Differentiation of adenocarcinoma: $\mathrm{G} 1$ = well differentiated; $\mathrm{G} 2$ = moderately differentiated; Muc = mucinous carcinoma. Circ $=$ circumferential tumor. 
Surgical and histopathological findings are shown in Table 2.

In this study, partial ISR, subtotal ISR, and total ISR were performed in 12,4 , and 14 patients, respectively. Furthermore, 4 of 11 patients (36.4\%) with T3 tumors intraoperatively decided to undergo additional partial ESR. The mean distance between the distal edge of the tumor and the dentate line was $8.9 \pm 8.0 \mathrm{~mm}$ (range, -3 to 25 $\mathrm{mm}$ ) in all the patients. Tumor location was significantly different for each ISR procedure (partial ISR, $16.0 \pm 4.6$ $\mathrm{mm}$; subtotal ISR, $5.0 \pm 4.1 \mathrm{~mm}$; total ISR, $3.5 \pm 5.1 \mathrm{~mm}$ ).

Assessment of the fixed surgical specimens revealed that the median distal edge of the tumor was $7 \mathrm{~mm}$ (range, 3 to $22 \mathrm{~mm}$ ), and it was negative in all cases. The median circumferential margin of the tumor was 3 $\mathrm{mm}$ (range, 0.5 to $9 \mathrm{~mm}$ ). The circumferential resection margin was positive $(<1 \mathrm{~mm})$ in two patients with T3 tumor without partial ESR. Reconstruction of the colonic J-pouch was performed in 26 patients, and straight coloanal anastomosis was performed in 4 patients due to narrow pelvis or bulky mesocolic fat tissue.

\section{Mortality and morbidity}

There was no mortality. Complications were encountered in ten patients (33.3\%). Anastomotic leakage occurred in seven patients, who were treated with perianal drainage. The colonic J-pouch prolapsed in two patients who underwent total ISR. One patient had an anovaginal fistula, requiring repair of fistula using perineal muscular rotation flap, and subsequent stoma closure. Anastomotic stricture or complete occlusion of an anastomosis occurred in seven patients. Of these seven patients, five

Table 2 Differences in clinicopathological characteristics between intersphincteric resection (ISR) procedures

\begin{tabular}{lccc}
\hline & $\begin{array}{c}\text { Partial ISR, } \\
(\mathbf{n}=\mathbf{1 1})\end{array}$ & $\begin{array}{c}\text { Subtotal ISR, } \\
(\mathbf{n}=\mathbf{4})\end{array}$ & $\begin{array}{c}\text { Total ISR, } \\
(\mathbf{n}=\mathbf{1 4})\end{array}$ \\
\hline Sex & & & \\
Male & 6 & 2 & 6 \\
Female & 6 & 2 & 8 \\
Type of reconstruction & & & \\
Colonic J-pouch & 9 & 4 & 13 \\
Straight & 3 & 0 & 1 \\
Combined with partial ESR & 0 & 2 & 2 \\
$\begin{array}{l}\text { Distance between the distal } \\
\text { edge of the tumor andthe }\end{array}$ & $16.0 \pm 4.6$ & $5.0 \pm 4.1$ & $3.5 \pm 5.1$ \\
dentate line, mm & & & \\
Distal resection margin, mm & & & \\
CRM, mm $^{\mathrm{a}}$ & $8.7 \pm 6.0$ & $9.5 \pm 10.5$ & $7.2 \pm 5.4$ \\
No. of stoma closures $^{\mathrm{b}}$ & $3.2 \pm 2.7$ & $4.8 \pm 3.1$ & $3.6 \pm 2.1$ \\
& $9(81.8)$ & $2(50)$ & $8(57.1)$ \\
\hline
\end{tabular}

Values indicate mean \pm SD.

${ }^{\mathrm{b}}$ Data in parentheses represent percentage values in each group.

$\mathrm{CRM}=$ circumferential resection margin; $\mathrm{ESR}=$ external sphincteric resection;

ISR = intersphincteric resection. patients required dilation of the anastomosis using finger bougie, endoscopic balloon dilation, or surgical stricture plasty before stoma closure. Two patients suffered complete occlusion of the anastomosis.

\section{Oncologic results}

Local, distant, and combined recurrence occurred in four, three, and two patients, respectively. Six patients died of cancer recurrence. For all patients who received ISR, the 5-year overall and disease-free survival rates were $76.5 \%$ and $68.4 \%$, respectively.

The median disease-free interval for six patients with local recurrence was 13 months (range, 8 to 14 months) (Table 3). All of the four isolated local recurrence episodes developed within the first 2 years. All the patients who experienced local recurrence had pT3 tumors, except one patient who had a pT2 tumor. The local recurrence rates were significantly lower in patients with Tis to T2 tumors $(5.2 \%)$ than in those with T3 tumors (45.5\%; $P=0.008$; Figure 1).

\section{Aspects of stoma closure}

Of the 29 ISR patients, excluding 1 with stage IVA disease, 19 (65.5\%) underwent stoma closure by February 2010, including 3 patients who had undergone straight anastomosis. The median interval between ISR and stoma closure was 7 months (range, 3 to 14 months). The median follow-up interval after stoma closure was 35 months (range, 4 to 68 months). Nine, two, and eight patients received stoma closure in the partial ISR, subtotal ISR, and total ISR groups, respectively (Table 2).

Definitive stoma closure could not be performed in 11 patients. Of the 11 patients, 5 had insufficient anal condition (complete anastomotic occlusions in 2, prolapse of colonic J-pouch in 2, obvious loose anastomosis in 1). The patients who developed colonic J-pouch prolapse or obvious loose anastomosis had received total ISR. Four patients were diagnosed with distant metastases or local relapse of the disease before stoma closure. Two patients did not undergo stoma closure for social reasons. Three out of four patients with additional partial ESR did not achieve stoma closure because of a colonic J-pouch prolapse or local recurrence.

\section{Evaluation of anal function}

Anal function was evaluated in 19 patients who underwent stoma closure. At 12 months after stoma closure, the mean Wexner score for all patients was 11.5 (range, 1 to 19). In the patients with partial ISR, the Wexner scores were improved from $13.0 \pm 3.1$ at 3 months to $12.1 \pm 3.0$ at 6 months $(P=0.04)$. In contrast, in the patients with subtotal or total ISR, no significant differences were found between the Wexner scores at 3 months and 6 months $(13.0 \pm 3.8$ and $11.5 \pm 4.9$, 
Table 3 Characteristics of six patients with local recurrence after intersphincteric resection (ISR)

\begin{tabular}{|c|c|c|c|c|c|c|c|c|c|c|}
\hline Patient & TNM & T stage & $\begin{array}{l}\text { Histological } \\
\text { type }\end{array}$ & $\begin{array}{l}\text { Surgical } \\
\text { procedure }\end{array}$ & $\begin{array}{c}\text { Distal } \\
\text { resection } \\
\text { margin, } \mathrm{mm}\end{array}$ & $\begin{array}{l}\text { Circumferential } \\
\text { resection margin, } \\
\text { mm }\end{array}$ & Localization & $\begin{array}{c}\text { Distant } \\
\text { metastases }\end{array}$ & Treatment & Outcome \\
\hline 1 & $\| \mathrm{A}$ & T3 & G2 & $\mathrm{tISR}+\mathrm{pESR}$ & 7 & 2 & Pelvic wall & NS & CRT & 45 months, $\mathrm{O}$ \\
\hline 2 & $\| \mathrm{IIB}$ & T3 & G2 & $s I S R+p E S R$ & 25 & 2 & Pelvic wall & NS & CRT & 70 months, S \\
\hline 3 & $\| I I B$ & T3 & G2 & pISR & 12 & 5 & Pelvic wall & Bone, lung & $C x$ & 31 months, $\mathrm{P}$ \\
\hline 4 & $\| \mathrm{A}$ & T3 & G2 & pISR & 10 & 0.5 & Lateral node & Adrenal gland & $C x$ & 36 months, $\mathrm{P}$ \\
\hline 5 & I & $\mathrm{T} 2$ & G1 & pISR & 3 & 6 & Anastomosis & NS & APR & 22 months, S \\
\hline 6 & $\| B$ & $\mathrm{~T} 3$ & G1 & pISR & 3 & 0.5 & Lateral node & NS & CRT & 17 months, S \\
\hline
\end{tabular}

Distal resection margins and circumferential resection margins were measured on the histological slides.

$\mathrm{APR}=$ abdominoperineal resection; $\mathrm{CRT}=$ chemoradiotherapy; $\mathrm{CX}=$ chemotherapy; $\mathrm{ESR}=$ external intersphincteric resection; ISR $=$ intersphincteric resection; $\mathrm{NS}=$ not stated; $\mathrm{O}=$ other origin of death; $\mathrm{P}=$ primary death; $\mathrm{S}=$ survived.

respectively; $P=0.14$ ), but an upward trend was observed in the Wexner scores at 6 months and 12 months $(11.5 \pm 4.9$ vs $9.1 \pm 5.6$, respectively, $P=0.06)$. At 3, 6, and 12 months, the Wexner scores were not significantly different between patients who underwent partial and subtotal or total ISR (Table 4). In the patients without anastomotic stricture, the Wexner scores were significantly improved at 6 months and 12 months compared with those at 3 months. However, five patients, including the one with subtotal ISR and an additional partial ESR, required finger bougie, endoscopic balloon dilation, or stricture plasty for anastomotic stricture, no improvement in the Wexner score was observed.

Table 5 shows the anal function based on the questionnaires answered at 3, 6, and 12 months after stoma closure, with or without anastomotic stricture. At 12 months after stoma closure, patients without anastomotic stricture were showed improved urgency (from $12 / 14$ to $3 / 12 ; P=0.008$ ) and nocturnal defecation (from $9 / 14$ to $5 / 12 ; P=0.014)$. However, patients with anastomotic stricture did not report improvement in any symptom. Compared to patients with anastomotic stricture, the non-stricture group showed significantly better results with

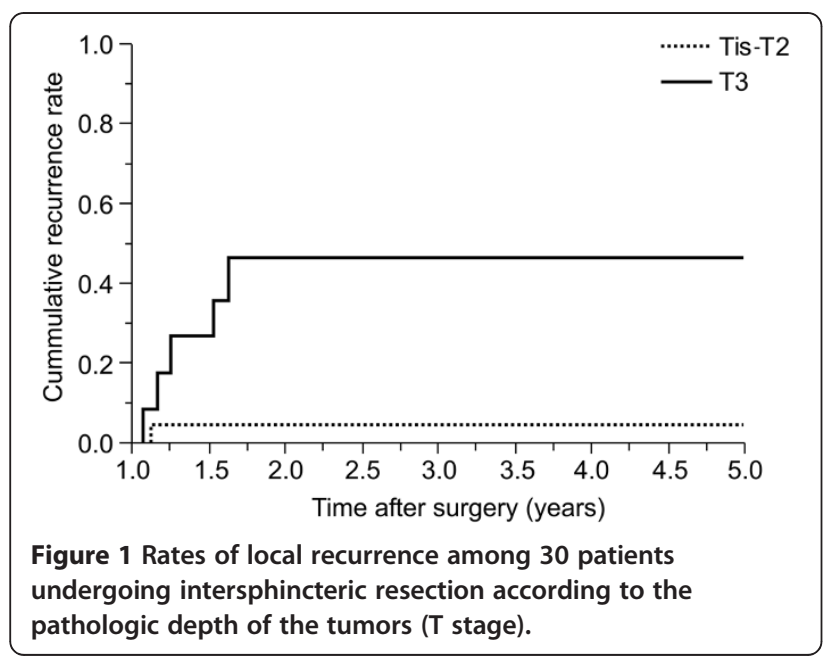

regard to stool frequency $(5.1 \pm 2.9$ vs $9.0 \pm 5.3 ; P=0.02)$, urgency $(3 / 12$ vs $4 / 5 ; P=0.04)$, and fragmentation $(4 / 12$ vs $5 / 5 ; P=0.015)$ at 12 months.

The results of the univariate analysis revealed that poor anal function, as assessed by the Wexner score, was significantly associated with gender (male; $P=0.047$ ) and the presence of anastomotic stricture $(P=0.018)$ at 12 months. The surgical procedure (partial or subtotal/total ISR), type of reconstruction (straight or colonic J-pouch), and age $(<70$ or $\geq 70)$ were not significantly associated with anal function. The results of the multivariate analysis also showed that gender $(P=0.283)$ was not significantly associated with anal function and that the presence of anastomotic stricture $(P=0.093)$ only demonstrated a trend towards being significantly associated with anal function (data not shown).

\section{Discussion}

Although ISR is the sphincter-preserving procedure for very low rectal cancer, there are concerns regarding local control and defecatory function. In this study, we report the outcomes of ISR of very low rectal cancer, less than $2.5 \mathrm{~cm}$ from the dentate line, with a median follow-up period of 56 months. Our data show that this operation is feasible, with no postoperative mortality found in the study group. Moreover, it is associated with favorable

Table 4 Wexner scores at 3, 6, and 12 months in patients who underwent intersphincteric resection (ISR) followed by stoma closure

\begin{tabular}{lccc}
\hline Procedure/findings & $\mathbf{3}$ months & $\mathbf{6}$ months & $\mathbf{1 2}$ months \\
\hline Surgical procedure & & & \\
$\quad$ Partial ISR $(\mathrm{n}=9)$ & $13.3 \pm 3.1$ & $12.1 \pm 3.0^{*}$ & $11.8 \pm 2.6$ \\
$\quad$ Subtotal or total ISR $(\mathrm{n}=10)$ & $13.0 \pm 3.8$ & $11.5 \pm 4.9$ & $9.1 \pm 5.6$ \\
Anastomotic stricture & & & \\
$\quad$ Yes $(\mathrm{n}=5)$ & $15.4 \pm 2.9$ & $13.4 \pm 4.5$ & $13.6 \pm 3.9$ \\
$\quad$ No $(\mathrm{n}=14)$ & $12.4 \pm 3.3$ & $11.2 \pm 3.9^{*}$ & $9.0 \pm 4.5^{*}$ \\
\hline
\end{tabular}

Data are shown as mean \pm SD. Data at 6 and 12 months were statistically compared with those at 3 months using the Wilcoxon signed-rank test. ${ }^{*} \mathrm{P}<0.05$. 
Table 5 Anal dysfunction after stoma closure in patients with anastomotic stricture and those with no anastomotic stricture

\begin{tabular}{|c|c|c|c|c|c|c|}
\hline \multirow{2}{*}{$\begin{array}{l}\text { Symptoms related to } \\
\text { anal function }\end{array}$} & \multicolumn{2}{|c|}{3 months } & \multicolumn{2}{|c|}{6 months } & \multicolumn{2}{|c|}{12 months } \\
\hline & Non-stricture & Stricture & Non-stricture & Stricture & Non-stricture & Stricture \\
\hline Stool frequency, times/day & $6.4 \pm 3.6$ & $11.4 \pm 3.0^{* *}$ & $6.8 \pm 2.8$ & $7.0 \pm 2.1$ & $5.1 \pm 2.9$ & $9.0 \pm 5.3^{* *}$ \\
\hline Urgency & $12 / 14$ & $4 / 5$ & $8 / 13$ & $2 / 5$ & $3 / 12^{*}$ & $4 / 5^{* *}$ \\
\hline Fragmentation & $10 / 14$ & $5 / 5$ & $7 / 13$ & $4 / 5$ & $4 / 12$ & $5 / 5^{* *}$ \\
\hline Dyschesia & $2 / 14$ & $3 / 5$ & $2 / 13$ & $0 / 5$ & $2 / 12$ & $0 / 5$ \\
\hline Medication use & $4 / 14$ & $4 / 5$ & $3 / 13$ & $4 / 5^{* *}$ & $2 / 12$ & $3 / 5$ \\
\hline Nocturnal defecation & $9 / 14$ & $5 / 5$ & $5 / 13^{*}$ & $5 / 5$ & $5 / 12^{*}$ & $4 / 5$ \\
\hline
\end{tabular}

Data associated with each anal dysfunction at 6 and 12 months were statistically compared with those at 3 months for each condition of anastomotic sites using Wilcoxon signed-rank test. * $\mathrm{P}<0.05$.

Data associated with each anal dysfunction of the stricture group were statistically compared with those of the non-stricture group at 3,6 , and 12 months using the Mann-Whitney $U$ test. ${ }^{* *} \mathrm{P}<0.05$.

oncological outcomes for Tis-T2 tumors. With regard to the Wexner score, total ISR did not produce worse outcomes than partial ISR did, with the exception that permanent stoma were necessitated by unfavorable anastomosis. However, anastomotic stricture, which occurred as a postoperative complication, was found to negatively affect anal function.

From an oncological point of view, local control of the disease remains the most important objective in rectal cancer surgery. The local recurrence rate of very low rectal cancer for ISR varied widely, ranging between $0 \%$ [23] to $31 \%$ [25]. With ISR, the rate of secure distal resection margin was in the range of $95 \%$ [23] to $100 \%$ [18], and our results showed a median distance of $7 \mathrm{~mm}$, and a definite negative distal margin in all patients. Therefore, ISR was found to provide an optimal distal resection margin, which is difficult to attain by using only the abdominal approach for very low rectal cancer. Rate of positive CRM of the rectal cancer also influenced factor of local recurrence. In our study group, $6.7 \%$ of all patients had a CRM $\leq 1 \mathrm{~mm}$, and similar results were reported in the range of $0 \%$ to $13.3 \%[18,26]$. Preoperative CRT was considered useful for preventing local recurrence in low rectal cancer patients requiring ISR $[14,23]$. Kuo et al. [26] reported a positive CRM rate of 13.3\%, but a local recurrence rate of $7.7 \%$ in their ISR series of 26 patients; $88.5 \%$ of these patients had undergone preoperative CRT. Paradoxically, Hohenberger and colleagues [27] reported that in ISR patients with lower-third rectal cancer without radiotherapy, the local recurrence rate was high, at $46.5 \%$. In our study, local recurrence was significantly higher in patients with T3 tumors than in those with Tis-T2 tumors. Akasu et al. [28] reported that both T3 tumors and a positive microscopic resection margin in patients who underwent ISR were significantly associated with local recurrence. Because ISR involves dissection of the rectum between the internal sphincter muscle and the external sphincter muscle, in patients with T3 tumors with expanding microscopic tumor cells near the levator ani or the external sphincter muscles, during surgical resection, there is a considerable risk of cutting into the tumor or achieving a very short distance of a few millimeters to the CRM. Thus, for a group of patients with T3 tumors, ISR was applied to attain good responses to neoadjuvant CRT, leading to secure CRM.

Partial or total resection of the internal sphincter muscle resulted in defecatory dysfunction with frequent defecation, urgency, and fecal incontinence $[16,18,29]$. Moreover, preoperative radiotherapy against T3 tumors or lymph node involvement was found to have a negative impact on anal function after ISR $[17,18,26]$. In the study by Ito et al. [17], of all the patients who underwent ISR, $40 \%$ received radiotherapy and were found to have a mean Wexner score of 10 at 12 months. Moreover, Denost et al. [20] reported a median Wexner score of 11 in most of the patients who received radiotherapy.

It has been shown that colonic J-pouch reconstruction in conjunction with ISR can minimize the anal dysfunctionrelated side effects of a sphincteric resection [9]. Hida et al. [30] reported the long-term benefits of colonic J-pouch reconstruction suggesting that it improves reservoir function to a greater extent than straight anastomosis does, especially in patients in whom the anastomosis is less than $4 \mathrm{~cm}$ from the anal verge. In addition, Dennett et al. [31] reported that colonic J-pouch is effective in very low rectal cancer surgery, causing apparent reduction in the incidence of anastomotic leaks and in bowel frequency. In our study, the mean Wexner score was 11.5 in most patients with colonic J-pouch reconstruction, and none of the patients had received radiation therapy. In previous studies, total ISR was performed in $8.9 \%$ [29] to $33.7 \%$ [20] of all the ISR patients. A possible reason for the poorer outcomes about Wexner score in our study was that the number of patients who required total ISR accounted for approximately half the ISR patients (42.1\%), because coloanal anastomosis using conventional DST was technically possible in a few patients who required partial ISR during our study period. 
The outcome for continence is reported to be worse after total ISR than after subtotal or partial ISR [19,20]. In our results for Wexner scores, anal function between total or subtotal ISR and partial ISR were not different, but patients of partial ISR had earlier recovery than those of subtotal or total ISR. Our functional results are limited because of the differences in stoma closure rates between partial ISR and subtotal/total ISR patients. The rates of stoma closure in patients with subtotal or total ISR were lower than those in patients undergoing partial ISR. This result in itself indicates poor anal function outcomes for subtotal/total ISR. Especially with respect to the three patients with total ISR, stoma closure was not possible because of the high risk of major incontinence.

Postoperative complication rates varied between reported series from $18 \%$ to $64 \%$ [15]. Common complications included leakage, anastomotic stricture, fistula, pelvic sepsis, and prolapse. In a previous literature review, anastomotic leakage rates of $5 \%$ to $48 \%$ [32] were reportedly associated with ISR, and they varied depending on whether asymptomatic leaks were radiologically detected. Also, Tilney and Tekkis [9] reviewed 21 studies and reported an overall anastomotic leak rate of 10.5\% and anastomotic stricture rate of $5.8 \%$. Similar rates were reported in the current series: anastomotic leakage occurred in 7 of 30 patients (23.3\%) and anastomotic stricture in $12 \%$ of the patients. Anastomotic leakage is an important feature since it has been found to lead to postoperative anastomotic stricture [33] and poor postoperative anorectal function [34]. However, in our study, there were no independent factors associated with anal dysfunction in the multivariate analysis, but patients with anastomotic stricture showed worse outcomes (frequency, urgency, and fragmentation) than patients without anastomotic stricture. In addition, symptoms related to anal function were not reduced in these patients. In our study, anastomotic stricture or occlusion occurred in five of seven patients with anastomotic leakage; thus, stricture formation could be attributed to leakage caused by ischemia or infection of the anastomotic site. Therefore, it is necessary to fully explain the possibility of fecal incontinence or of a permanent stoma to the patients before obtaining informed consent. Fecal QOL in our patients who had an anastomotic stricture was worse, and they might have little benefit from preserving the anal continuity with ISR.

Our study has some limitations: it was a retrospective study and the sample size was relatively small. There could be potential bias due to possible difference between those who were ambitious of receiving the anal sphincter preserving surgery and those who did not, which could affect the self-evaluation for gastrointestinal questionnaire. With regard to the additional partial ESR performed only in one patient with stoma closure, this was not taken into consideration while estimating anal function.

\section{Conclusions}

In summary, ISR is an oncologically safe procedure for pTis or pT2 tumors among very low rectal cancer patients. Also, total ISR, that is, complete removal of the internal sphincter muscles, carried risks of worse anal function or possibility of a permanent stoma. The complications associated with anastomosis, especially stenosis, resulted in poorer anal function. Larger studies are needed to evaluate functional results in ISR patients who suffer from anastomotic stricture.

\section{Abbreviations}

CRM: circumferential resection margin; DST: double-stapling technique; ESR: external sphincter resection; ISR: intersphincteric resection; TME: total mesorectal excision.

\section{Competing interests}

The authors declare they have no competing interests.

\section{Authors' contributions}

$\Pi$, KO, JH, KU, TY, KD, MT, FS: made substantial contributions to conception and design, and/or acquisition of data, and/or analysis and interpretation of data. $\Pi$, KO, JH: drafted the article and revised it critically for important intellectual content. $\Pi$ T, $K O, J H, K U, T Y, K D, M K$, FS: responsible for final approval of the manuscript. All authors read and approved the final manuscript.

\section{Acknowledgements}

We thank all the members of the Department of Pathology at our institute for conducting the pathological investigations for this study.

Received: 5 September 2012 Accepted: 14 January 2013

Published: 28 January 2013

\section{References}

1. Heald RJ, Ryall RD: Recurrence and survival after total mesorectal excision for rectal cancer. Lancet 1986, 1:1479-1482.

2. Cohen Z, Myers E, Langer B, Taylor B, Railton RH, Jamieson C: Double stapling technique for low anterior resection. Dis Colon Rectum 1983, 26:231-235.

3. Lavery IC, Lopez-Kostner F, Fazio WW, Fernandez-Martin M, Milsom JW, Church JM: Chances of cure are not compromised with sphincter-saving procedures for cancer of the lower third of the rectum. Surgery 1997, 122:779-785.

4. Gamagami RA, Liagre A, Chiotasso P, Istvan G, Lazorthes F: Coloanal anastomosis for distal third rectal cancer: prospective study of oncologic results. Dis Colon Rectum 1999, 42:1272-1275.

5. Berge A, Tiret E, Cunningham C, Dehni N, Parc R: Rectal excision and colonic pouch-anal anastomosis for rectal cancer: oncologic results at five years. Dis Colon Rectum 1999, 42:1265-1271.

6. Schiessel R, Kamer-Hanusch J, Herbst F, Teleky B, Wunderlich M: Intersphincteric resection for low rectal tumours. Br J Surg 1994, 81:1376-1378.

7. Teramoto T, Watanabe M, Kitajima M: Per anum intersphinctric rectal dissection with direct coloanal anastomosis for lower rectal cancer: the ultimate sphincter-preserving operation. Dis Colon Rectum 1997, 40:S43-S47.

8. Köhler A, Athanasiadis S, Ommer A, Psarakis E: Long-term results of low anterior resection with intersphincteric anastomosis in carcinoma of the lower one-third of the rectum: analysis of 31 patients. Dis Colon Rectum 2000, 43:843-850.

9. Tilney HS, Tekkis PP: Extending the horizons of restorative rectal surgery: intersphincteric resection for low rectal cancer. Colorectal Dis 2008, 10:3-16.

10. Rullier E, Zerbib F, Laurent C, Bonnel C, Caudry M, Saric J, Parneix M: Intersphincteric resection with excision of internal anal sphincter for 
conservative treatment of very low rectal cancer. Dis Colon Rectum 1999, 42:1168-1175.

11. Saito $N$, Ono M, Sugito M, Ito M, Morihiro M, Kosugi C, Sato K, Kotaka M, Nomura S, Arai M, Kobatake T: Early results of intersphincteric resection for patients with very low rectal cancer: An active approach to avoid a permanent colostomy. Dis Colon Rectum 2004, 47:459-466.

12. Ueno H, Mochizuki $H$, Hashiguchi $Y$, Ishikawa K, Fujimoto $H$, Shinto E, Hase $\mathrm{K}$ : Preoperative parameters expanding the indication of sphincter preserving surgery in patients with advanced low rectal cancer. Ann Surg 2004, 239:34-42.

13. Rullier E, Laurent C, Bretagnol F, Rullier A, Vendrely V, Zerbib F: Sphinctersaving resection for all rectal carcinomas -The end of the $2-\mathrm{cm}$ distal rule. Ann Surg 2005, 241:465-469.

14. Rullier E, Goffre B, Bonnel C, Zerbib F, Caudry M, Saric J: Preoperative radiochemotherapy and sphincter-saving resection for T3 carcinomas of the lower third of the rectum. Ann Surg 2001, 234:633-640.

15. Tiret E, Poupardin B, McNamara D, Dehni N, Parc R: Ultralow anterior resection with intersphincteric dissection-what is the limit of safe sphincter preservation? Colorectal Dis 2003, 5:454-457.

16. Bretagnol F, Rullier E, Laurent C, Laurent C, Zerbib F, Gontier R, Saric J: Comparison of functional results and quality of life between intersphincteric resection and conventional coloanal anastomosis for low rectal cancer. Dis Colon Rectum 2004, 47:832-838.

17. Ito M, Saito N, Sugito M, Kobayashi A, Nishizawa Y, Tsunoda Y: Analysis of clinical factors associated with anal function after intersphincteric resection for very low rectal cancer. Dis Colon Rectum 2009, 52:64-70.

18. Chamlou R, Parc Y, Simon T, Bennis M, Dehni N, Parc R, Tiret E: Long-term results of intersphincteric resection for low rectal cancer. Ann Surg 2007 246:916-922.

19. Yamada K, Ogata S, Saiki Y, Fukunaga M, Tsuji Y, Takano M: Functional results of intersphincteric resection for low rectal cancer. Br J Surg 2007, 94:1272-1277.

20. Denost Q, Laurent C, Capdepont M, Zerbib F, Rullier E: Risk factor for fecal incontinence after intersphincteric resection for rectal cancer. Dis Colon Rectum 2011, 54:963-968.

21. Colquhoun P, Kaizer R Jr, Efron J, Weiss EG, Nogueras JJ, Vernava AM, Vernava AM 3rd, Wexner SD: Is the quality of life better in patients with colostomy than patients with fecal incontinence? World J Surg 2006 30:1925-1928

22. Sobin LH, Gospodarowicz M, Wittekind C: UICC: TNM classification of malignant tumors. 7th edition. New York, NY: Wiley-Liss; 2009:100-109.

23. Weiser MR, Quah HM, Shia J, Guillem JG, Paty PB, Temple LK, Goodman KA, Minsky BD, Wong WD: Sphincter preservation in low rectal cancer is facilitated by preoperative chemoradiation and intersphincteric dissection. Ann Surg 2009, 249:236-242.

24. Jorge JM, Wexner SD: Etiology and management of fecal incontinence. Dis Colon Rectum 1993, 36:77-97.

25. Yoo JH, Hasegawa H, Ishii $Y$, Nishibori H, Watanabe M, Kitajima M: Long-term outcome of per anum intersphincteric rectal dissection with direct coloanal anastomosis for lower rectal cancer. Colorectal Dis 2005, 7:434-440.

26. Kuo LJ, Hung CS, Wu CH, Wang W, Tam KW, Liang HH, Chang YJ, Wei PL. Oncological and functional outcomes of intersphincteric resection for low rectal cancer. J Surg Res 2011, 170:e93-e98.

27. Hohenberger W, Merkel S, Matzel K, Bittorf B, Papadopoulos T, Göhl J: The influence of abdomino-peranal (intersphincteric) resection of lower third rectal carcinoma on the rates of sphincter preservation and locoregional recurrence. Colorectal Dis 2006, 8:23-33.

28. Akasu T, Takawa M, Yamamoto S, Fujita S, Moriya Y: Incidence and patterns of recurrence after intersphincteric resection for very low rectal adenocarcinoma. J Am Coll Surg 2007, 205:642-647.

29. Barisic G, Markovic M, Popovic M, Dimitrijevic I, Gavrilovic P, Krivokapic Z: Function after intersphincteric resection for low rectal cancer and its influence on quality of life. Colorectal Dis 2011, 13:638-643.

30. Hida J, Yoshifuji T, Tokoro T, Inoue K, Matsuzaki T, Okuno K, Shiozaki H, Yasutomi M: Comparison of long-term functional results of colonic Jpouch and straight anastomosis after low anterior resection for recta cancer: a five-year follow-up. Dis Colon Rectum 2004, 47:1578-1585.

31. Dennett ER, Parry BR: Misconceptions about the colonic J-pouch: what the accumulating data show. Dis Colon Rectum 1999, 42:804-811.
32. Martin ST, Heneghan HM, Winter DC: Systematic review of outcomes after intersphincteric resection for low rectal cancer. British J Surg 2012, 99:603-612.

33. Tuson JR, Everett WG: A retrospective study of colostomies, leaks and strictures after colorectal anastomosis. Int J Colorectal Dis 1990, 5:44-48.

34. Nesbakken A, Nygaard K, Lunde OC: Outcome and late functional results after anastomotic leakage following mesorectal excision for rectal cancer. Br J Surg 2001, 88:400-404.

doi:10.1186/1477-7819-11-24

Cite this article as: Tokoro et al: Analysis of the clinical factors associated with anal function after intersphincteric resection for very low rectal cancer. World Journal of Surgical Oncology 2013 11:24

\section{Submit your next manuscript to BioMed Central and take full advantage of:}

- Convenient online submission

- Thorough peer review

- No space constraints or color figure charges

- Immediate publication on acceptance

- Inclusion in PubMed, CAS, Scopus and Google Scholar

- Research which is freely available for redistribution 